\title{
Application of a cold patch for relieving pain after transepithelial photorefractive keratectomy
}

\author{
Yuan Zeng MSc ${ }^{1}$, Yi Li PhD², Jian-Hua Gao MSc ${ }^{3}$
}

\author{
Y Zeng, Y Li, J-H Gao. Application of a cold patch for relieving \\ pain after transepithelial photorefractive keratectomy. Pain Res \\ Manag 2015;20(4):195-198.
}

BACKGROUND: A return toward toward photorefractive keratectomy has occurred due to better corneal stability and fewer corneal flap complications; however, pain remains a major drawback of the procedure. Currently, clinical pain control measures focus on the administration of pain medications, which may delay corneal epithelial healing and has, occasionally, led to serious corneal toxicity.

OBJECTIVES: To investigate the safety and efficacy of a cold patch on postoperative pain and other relevant consequences of transepithelial photorefractive keratectomy.

METHODS: A prospective, randomized controlled study was conducted. Forty patients ( 80 eyes) scheduled to undergo transepithelial photorefractive keratectomy for myopia or myopic astigmatism were randomly and equally assigned to be treated with ice-cold balanced salt solution during surgery (wash group) or to wear a postoperative cold patch on the eye for $24 \mathrm{~h}$. The main outcomes were pain score on a visual analogue scale, postoperative eyelid edema, conjunctival hyperemia, epithelial healing time, haze and postoperative best-corrected visual acuity.

RESULTS: All patients completed the final tests. Demographic characteristics and pain scores during surgery were similar between the two groups. The mean postoperative pain scores of patients in the cold patch group at $8 \mathrm{~h}, 16 \mathrm{~h}$ and $24 \mathrm{~h}$ were significantly lower than those of patients in the wash group. Scores for postoperative eyelid edema and conjunctival hyperemia in the cold patch group were also lower than in the wash group. Patients in the cold patch group used fewer painkillers. Epithelial healing time, haze and early recovery of visual acuity were similar between the two groups. No eyelid frostbite was observed.

CONCLUSION: Wearing a cold patch on the eye after transepithelial photorefractive keratectomy effectively relieved pain and inflammation, and reduced the use of painkillers without any side effects.

Key Words: Cold patch; Pain management; Physical therapy; Transepithelial photorefractive keratectomy

\section{L'application d'un timbre froid pour soulager la douleur après une kératectomie photoréfractive transépithéliale}

HISTORIQUE : La kératectomie photoréactive transépithéliale a recom-
mencé à être utilisée en raison d'une meilleure stabilité de la cornée et du
moins grand nombre de complications des lambeaux cornéens. Toutefois,
la douleur demeure un inconvénient majeur de l'intervention. Les mesures
de contrôle clinique de la douleur sont axées sur l'administration
d'analgésiques qui peuvent retarder la cicatrisation épithéliale de la cornée
et qui ont parfois suscité une grave toxicité cornéenne. OBJECTIFS : Explorer l'innocuité et l'efficacité d'un timbre froid pour soulager la douleur postopératoire et les autres inconvénients de la kératectomie photoréfractive transépithéliale.

MÉTHODOLOGIE : Les chercheurs ont réalisé une étude aléatoire et contrôlée prospective. Quarante patients ( 80 yeux) qui devaient subir une kératectomie photoréfractive transépithéliale pour corriger une myopie ou un astigmatisme myopique ont été répartis au hasard en deux groupes égaux. L'un a reçu un traitement de solution saline équilibrée glacée pendant l'opération (groupe de lavage) et l'autre a porté un timbre froid sur l'œil pendant 24 heures après l'opération. Les principaux résultats étaient le score de la douleur selon l'échelle analogique visuelle, l'œè̀me de la paupière après l'opération, l'hyperémie conjonctivale, le délai de cicatrisation épithéliale, la vision floue et la correction de l'acuité visuelle après l'opération.

RÉSULTATS : Tous les patients ont effectué les tests finaux. Les deux groupes partageaient des caractéristiques démographiques et des scores de douleur similaires pendant l'opération. Les scores moyens de douleur postopératoire des patients du groupe ayant un timbre froid au bout de huit heures, 16 heures et 24 heures étaient beaucoup plus faibles que ceux des patients du groupe de lavage. Les scores d'œdème de la paupière et d'hyperémie conjonctivale après l'opération étaient également plus faibles dans le groupe ayant un timbre froid que dans le groupe de lavage. Les patients du groupe ayant un timbre froid prenaient moins d'analgésiques. Le délai de cicatrisation épithéliale, la vision floue et la récupération rapide de l'acuité visuelle étaient similaires dans les deux groupes. On n'a observé aucune engelure de la paupière.

CONCLUSION: Le port d'un timbre froid sur l'œil après la kératectomie photoréfractive transépithéliale soulage la douleur et l'inflammation et réduit le recours aux analgésiques sans causer d'effets secondaires.

surface ablation, involves the creation of a permanent flap in the deeper layer of the cornea. The LASIK technique has gradually surpassed corneal surface ablation to become the world's most popular refractive surgery (1). Nevertheless, a return toward corneal surface ablation has occurred due to better corneal stability $(2,3)$ and no corneal flap complications when compared with LASIK (4-7). For patients with epithelial basement membrane diseases; thin, flat or steep corneas; and professional athletes who incur risks for physical contact, corneal surface ablation is preferred for correcting refractive errors (8). It has been reported that corneal surface ablation is the most commonly performed refractive surgery among members of the United States Air Force (9-11). cedures; accordingly, they are referred to as corneal surface ablation. LASIK, a procedure that was developed later and is distinct from

${ }^{1}$ Department of Ophthalmology, Chinese PLA General Hospital and Chinese PLA Medical School, Beijing; ${ }^{2}$ Department of Oncology;

${ }^{3}$ Department of Ophthalmology, Kunming General Hospital of Chengdu Command, Kunming, China

Correspondence: Mr Yuan Zeng, Room 801, 25 Xinwen Road, Wuhua District, Kunming City, Yunnan Province, China, 650032.

Telephone 86-13033379313, e-mail zengyuan43@163.com 


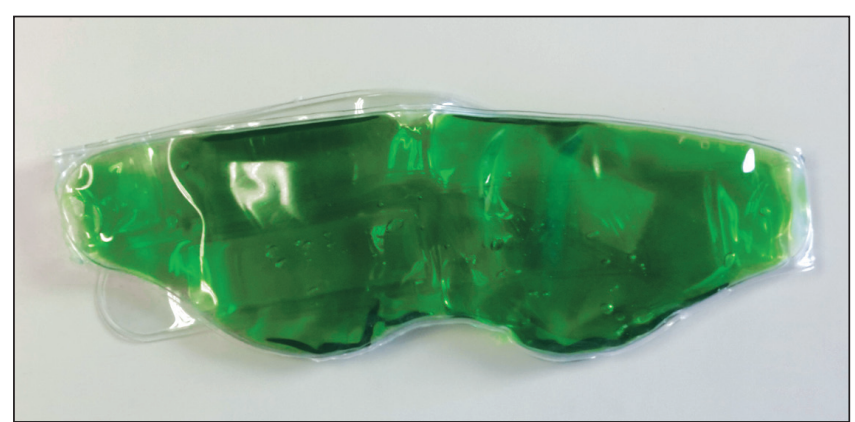

Figure 1) The outer surface of the cold patch is made from soft polyvinyl chloride material. It is filled with antifreeze gel, which does not freeze, even in environments in which the ambient temperature is $<0^{\circ} \mathrm{C}$

Pain is one of the most common postoperative complications of refractive surgeries, especially after corneal surface ablation (12). Most patients experience various degrees of postoperative pain, which can last up to $24 \mathrm{~h}$. Accompanying symptoms include foreign body sensation, photophobia, tearing, stinging, itching and burning sensations. Currently, clinical pain control measures focus on the wearing of an eye-bandage contact lens and administration of pain medications. Given the potential side effects and risks associated with pain medications (13-15), we conducted the present study to assess the efficacy and safety of a cold patch for treating postoperative pain after trans-PRK.

\section{Patients}

\section{METHODS}

The present prospective, randomized controlled study was performed in the Department of Ophthalmology, Kunming General Hospital of Chengdu Military Command, Kunming, Yunnan, China. From March to April 2012, 40 consecutive patients scheduled to undergo refractive surgery for myopia or myopic astigmatism were recruited.

The 40 patients ( 80 eyes) were randomly assigned to a cold patch group and a wash group (20 patients, 40 eyes each). Patients in the wash (control) group were administered $15 \mathrm{~mL}$ of ice-cold balanced salt solution (BSS) during the surgery, but no cold patch was provided after the surgery. Patients in the cold patch group wore a cold patch after the surgery constructed from polyvinyl chloride and filled with cooled antifreeze (Figures 1 and 2), and were not administered BSS during the surgery.

For inclusion in the study, patients had to be $\geq 18$ years of age; with myopia $\leq-6 \mathrm{D}$ diopter; with stable refractive myopia or myopic astigmatism for $>2$ years; and who had stopped wearing soft contact lenses for $\geq 2$ weeks or hard contact lenses for $\geq 4$ weeks before surgery. Patients were excluded if they had a history of eye surgery; had eye diseases such as active anterior segment disease, suspicious keratoconus detected by corneal topography, keratoconus, keratitis, cataracts, glaucoma or ocular fundus diseases; had a systemic disease that affects corneal wound healing such as lupus or diabetes; and if they were pregnant or breastfeeding.

All patients provided signed informed consent before surgery.

\section{Preoperative examination}

All patients underwent comprehensive ocular examinations before surgery, including uncorrected visual acuity (UCVA), best corrected visual acuity (BCVA), subjective refraction using phoropter, anterior segment evaluation using slit-lamp examination, intraocular pressure measurement, tear film breakup time measurement, corneal thickness measurement using ultrasonography and a dilated fundus examination.

\section{Surgical procedures}

After topical anesthesia with oxybuprocaine, the operated cornea was flushed with BSS (Alcon, USA) and dried carefully using a triangle sponge until the reflection of the corneal surface was uniform, and

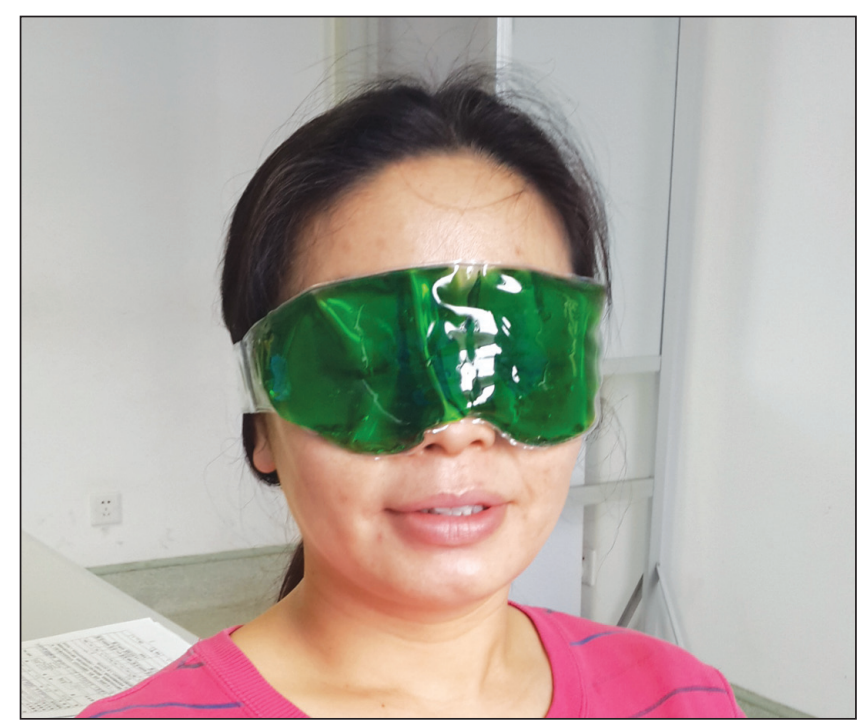

Figure 2) A patient wearing a cold patch while sitting. Velcro at both ends of the cold patch fixes the patch on the occiput, which ensures that patients can be in any position while wearing the cold patch.

there was no tear film or crumbs. The corneal epithelium was then removed using the laser; the cutting was stopped when the fluorescence of the corneal epithelium disappeared. The average cut size was $6.5 \mathrm{~mm}$ with a depth of $50 \mu \mathrm{m}$ to $70 \mu \mathrm{m}$.

After cutting, the wound was flushed with $15 \mathrm{~mL}$ ice-cold $\left(5^{\circ} \mathrm{C}\right)$ BSS in the wash group, and eye-bandage contact lenses (Bausch, USA) were worn on all eyes. Eyes in the cold patch group were also covered with bandage contact lenses. Instead of being flushed with ice-cold BSS, the patients in the cold patch group were required to wear a cold patch (cooled to $5^{\circ} \mathrm{C}$ to $8^{\circ} \mathrm{C}$ ) for $24 \mathrm{~h}$ after the surgery. After wearing the cold patch for $30 \mathrm{~min}$, patients were instructed to place it in a refrigerator to cool it for $30 \mathrm{~min}$, then to take it out and put it on again. This procedure was continued until the patients went to sleep in the first $24 \mathrm{~h}$ postoperatively.

Postoperative medications included topical tobramycin dexamethasone, levofloxacin, pranoprofen and recombinant human epidermal growth factor eyedrops. Topical oxybuprocaine eyedrops and oral diclofenac sodium were also applied to relieve pain in some patients if they complained of eye pain $24 \mathrm{~h}$ after surgery. Oxybuprocaine eyedrops were given for at least $2 \mathrm{~h}$ and diclofenac sodium capsules were given (<100 mg daily).

\section{Postoperative measurements}

The pain scores for each patient were recorded during surgery, and at $8 \mathrm{~h}, 16 \mathrm{~h}$ and $24 \mathrm{~h}$ after the surgery. Pain was evaluated using a 11 -point visual analogue scale $(0=$ no pain, $10=$ worst possible pain $)$.

Evaluation of postoperative eyelid edema was performed using a four-point score: 0 = no palpebral edema; 1 = mild eyelid edema, palpebral fissure was not reduced significantly; $2=$ moderate eyelid edema, palpebral fissure narrowed considerably; 3 = severe eyelid edema, palpebral fissure disappeared.

Following surgery, corneal epithelial healing was observed by slitlamp every $24 \mathrm{~h}$ until the epithelium was completely healed. Postoperative conjunctival hyperemia was assessed and recorded according to the following criteria: 0 = no conjunctival hyperemia; $1=$ minor conjunctival hyperemia, only in the nasal or temporal side close to the limbus; 2 = conjunctival hyperemia limited to two quadrants; 3 = conjunctival hyperemia spread to four quadrants; 4 = heavy conjunctival hyperemia involving four quadrants with prolapsed edematous conjunctiva.

UCVA, BCVA, manifest refractive spherical equivalent (MRSE) and haze were also recorded in the first and sixth months after surgery, respectively. 
TABLE 1

\begin{tabular}{|c|c|c|c|}
\hline & Cold patch $(n=20)$ & BSS wash $(n=20)$ & $\mathbf{P}$ \\
\hline During surgery & $2.56 \pm 1.29$ & $2.89 \pm 1.51$ & 0.46 \\
\hline \multicolumn{4}{|l|}{ Postoperative } \\
\hline $8 \mathrm{~h}$ & $2.32 \pm 1.31$ & $3.41 \pm 1.63$ & 0.025 \\
\hline $16 \mathrm{~h}$ & $2.16 \pm 0.81$ & $3.25 \pm 1.03$ & 0.001 \\
\hline $24 \mathrm{~h}$ & $1.16 \pm 0.68$ & $2.02 \pm 0.79$ & 0.001 \\
\hline
\end{tabular}

Data presented as mean $\pm S D$ unless otherwise indicated. BSS Balanced salt solution

Statistical analysis

Data analysis was performed using SPSS version 19.0 (IBM Corporation, USA). An independent-samples $t$ test was used to compare differences in eyelid swelling between the two groups; $P<0.05$ was considered to be statistically significant.

\section{RESULTS}

All 40 patients included in the present study completed the tests. There was no statistically significant difference in age or degree of MRSE between the two groups. The mean $( \pm$ SD) age of the patients was $25.5 \pm 5.2$ years in the cold patch group and $26.2 \pm 3.7$ years in the wash group $(P=0.63)$. The degree of MRSE was $-3.85 \pm 1.75$ diopter in the cold patch group and $-4.19 \pm 1.56$ diopter in the wash group $(\mathrm{P}=0.36)$.

The mean epithelium cutting depth was $57.2 \pm 16.6 \mu \mathrm{m}$ in the cold patch group and $58.4 \pm 16.8 \mu \mathrm{m}$ in the wash group, a difference that was not statistically significant $(\mathrm{P}=0.75)$. The mean epithelium healing time was 2.6 \pm 0.5 days in the cold patch group and $2.8 \pm 0.6$ days in the wash group; the difference was not statistically significant $(\mathrm{P}=0.11)$.

As shown in Table 1, the pain scores of both groups during the surgery were comparable $(\mathrm{P}=0.46)$. It was noteworthy that the pain scores in the cold patch group at $8 \mathrm{~h}, 16 \mathrm{~h}$ and $24 \mathrm{~h}$ postoperatively were all significantly lower than those in the wash group. Pain relief was evident in all patients $24 \mathrm{~h}$ after surgery.

One day after surgery, mean scores for eyelid edema were $0.63 \pm 0.34$ in the cold patch group and $1.26 \pm 0.41$ in the wash group; this difference was statistically significant $(\mathrm{P}<0.001)$. No eyelid frostbite occurred in the cold patch group. In addition, the conjunctival hyperemia level was $0.85 \pm 0.37$ in the cold patch group and $1.57 \pm 0.51$ in the wash group $(\mathrm{P}<0.001)$.

Regarding the use of painkillers, oxybuprocaine eyedrops were applied $2.32 \pm 0.56$ times in the cold patch group and 5.61 \pm 1.24 times in the wash group. The cold patch group was administered a mean of $1.22 \pm 0.25$ oral diclofenac sodium capsules and $2.18 \pm 0.47$ capsules were given to the wash group $(\mathrm{P}<0.001)$.

As shown in Table 2, the UCVA, BCVA, and refractive error and haze of both groups recorded in the first and sixth months after surgery were also not statistically different. Haze was not detected in any eye six months after surgery.

\section{DISCUSSION}

Trans-PRK reduces the risk of corneal ectasia and avoids the corneal flap complications associated with LASIK surgery; however, the postoperative pain associated with trans-PRK cannot be ignored. The present study showed that wearing a cold patch after trans-PRK significantly reduced scores for pain and postoperative complications compared with washing with ice-cold BSS during surgery. Moreover, the patients who wore the cold patch used less pain medication.

Clinically, a variety of eye drops or medications are used to relieve pain including nonsteroidal anti-inflammatory drugs, which reduce prostaglandin release by inhibiting cyclooxygenase; glucocorticoids, which
TABLE 2

Comparison of postoperative uncorrected visual acuity (UCVA), best corrected visual acuity (BCVA), mean refractive spherical equivalent (MRSE) error and haze between the cold patch $(n=40)$ and wash $(n=40)$ groups one and six months after surgery

\begin{tabular}{lccccccc}
\hline & \multicolumn{3}{c}{ One month } & \multicolumn{3}{c}{ Six months } \\
\cline { 2 - 4 } & Cold patch & BSS wash & $\mathbf{P}$ & & Cold patch & BSS wash & $\mathbf{P}$ \\
\hline UCVA & $0.91 \pm 0.24$ & $0.83 \pm 0.23$ & 0.13 & & $1.02 \pm 0.21$ & $0.98 \pm 0.26$ & 0.45 \\
BCVA & $0.96 \pm 0.36$ & $0.89 \pm 0.40$ & 0.41 & & $1.16 \pm 0.19$ & $1.04 \pm 0.17$ & 0.62 \\
MRSE (D) & $0.86 \pm 0.24$ & $0.82 \pm 0.31$ & 0.52 & & $0.42 \pm 0.30$ & $0.50 \pm 0.37$ & 0.29 \\
Haze & $0.22 \pm 0.14$ & $0.26 \pm 0.17$ & 0.25 & & None & None & - \\
\hline
\end{tabular}

Data presented as mean \pm SD unless otherwise indicated. BSS Balanced salt solution; D Diopter

reduce stimulation of multiple receptors by inhibiting prostaglandins and many inflammatory mediators such as leukotrienes and bradykinin, and interleukin synthesis (16). Local application of topical anesthesia drugs relieves pain by inhibiting sodium-potassium channels and blocking the transmission of nerve impulses. Although all of the above-mentioned drugs can relieve pain, regardless of local, topical or systemic administration, all have associated side effects and risks. For example, topical anesthesia drug abuse can cause delayed corneal epithelial healing, and nonsteroidal anti-inflammatory drugs have occasionally led to serious corneal toxicity (17-19). Side effects of oral painkillers include kidney failure, peptic ulcers, constipation, pruritus, dizziness, nausea, vomiting and dry mouth $(20,21)$. Therefore, it is necessary to investigate new methods with fewer and less-severe side effects and risks to relieve the postoperative pain associated with trans-PRK.

Presently, there are few studies that have investigated pain relief using physical therapy after laser surface ablation. The mechanism of local hypothermia for pain control involves reducing the transmission of nerve impulses by lowering the temperature, which is similar to that of topical anesthesia. Currently, local hypothermia for alleviating pain is achieved by washing the corneal wound with ice-cold BSS before and after laser cutting. Animal experiments have shown that washing with ice-cold BSS can significantly decrease the temperature of corneas in a rabbit model (22). Many surgeons recommend that patients use eyedrops of cold artificial tears to reduce pain after surgery $(23,24)$; however, another study reached the opposite conclusion. Neuffer et al (25) found no significant difference in the application of ice-cold or warm BSS during LASEK in a prospective, randomized single-blinded study.

Cold compress is another physical therapy used to relieve pain. Cold water or ice can cool, effect hemostasis, relieve pain, reduce inflammation and promote wound healing. Fujishima et al (26) applied cold compresses using ice packs on the eyes for cataract surgery and concluded that most patients were satisfied with this type of physical therapy to relieve pain. Cold compresses work by quickly reducing the surface temperature of the wound. The low temperature leads to local vasoconstriction, a decrease in metabolism, and a decrease in vascular inflammatory factors and bleeding, which inhibit edema. In addition, cold compresses are inexpensive and easy to apply.

The most commonly used cold compress in current clinical practice is the ice pack. However, keeping the ice pack in place is difficult, and the patient's movement is limited. If the ice pack is improperly used, frostbite is possible. Therefore, in the present study, we used a cold patch made from soft polyvinyl chloride material filled with antifreeze gel. This antifreeze gel ensures that the cold patch does not freeze, even if the ambient temperature is $<0^{\circ}$ (Figure 1). When patients wear a cold patch, they can be in any position because velcro strips at both ends of the cold patch can be used to fix the patch to the occiput (Figure 2). Patients can even fall asleep when wearing the cold patch. In our study, no patient experienced eyelid frostbite. We speculate that this is due to the abundant blood flow in the eyelid. 
A potential limitation of the present study was that we did not compare the corneal temperatures of the two groups due to the lack of appropriate instruments. Although the influence of this limitation on our conclusions is negligible, we will attempt to perform a comparison of corneal temperatures in future work if the instruments become available.

\section{SUMMARY}

Wearing a cold patch, as described in the present article, can increase comfort in the surgically treated eyes and reduce the use of pain medication. The cold patch is an effective, safe physical therapy that alleviates eye pain and inflammation after trans-PRK.

\section{REFERENCES}

1. Duffey RJ, Leaming D. US trends in refractive surgery: 2003 ISRS/AAO survey. J Refract Surg 2005;21:87-91.

2. Ivarsen A, Hjortdal J. Seven-year changes in corneal power and aberrations after PRK or LASIK. Invest Ophthalmol Vis Sci 2012;53:6011-6.

3. Hodge C, Lawless M, Sutton G. Keratectasia following LASIK in a patient with uncomplicated PRK in the fellow eye. J Cataract Refract Surg 2011;37:603-7.

4. Khoueir Z, Haddad NM, Saad A, Chelala E, Warrak E. Traumatic flap dislocation 10 years after LASIK. Case report and literature review. J Fr Ophtalmol 2013;36:82-6.

5. Kim HJ, Silverman CM. Traumatic dislocation of LASIK flaps 4 and 9 years after surgery. J Refract Surg 2010;26:447-52.

6. Grezda A, Mema V, Jaho J, Dai J. Traumatic corneal flap displacement five years after laser in situ keratomileusis. Hippokratia 2010;14:48-50.

7. Holt DG, Sikder S, Mifflin MD. Surgical management of traumatic LASIK flap dislocation with macrostriae and epithelial ingrowth 14 years postoperatively. J Cataract Refract Surg 2012;38:357-61.

8. Ambrósio R, Wilson S. LASIK vs LASEK vs PRK: Advantages and indications. Semin Ophthalmol 2003;18:2-10.

9. Hammond MD, Madigan WP, Bower KS. Refractive surgery in the United States Army, 2000-2003. Ophthalmology 2005;112:184-90.

10. Panday VA, Reilly CD. Refractive surgery in the United States Air Force. Curr Opin Ophthalmol 2009;20:242-6.
11. Stanley PF, Tanzer DJ, Schallhorn SC. Laser refractive surgery in the United States Navy. Curr Opin Ophthalmol 2008;19:321-4.

12. McCarty CA, Garrett SK, Aldred GF, Taylor HR. Assessment of subjective pain following photorefractive keratectomy. Melbourne Excimer Laser Group. J Refract Surg 1996;12:365-9.

13. Bischoff G, Brocks U. [Contact lenses and keratitis]. Klin Monbl Augenheilkd 2012;229:514-20.

14. Lee JK, Stark WJ. Anesthetic keratopathy after photorefractive keratectomy. J Cataract Refract Surg 2008;34:1803-5.

15. Kim JY, Choi YS, Lee JH. Keratitis from corneal anesthetic abuse after photorefractive keratectomy. J Cataract Refract Surg 1997;23:447-9.

16. Vane J, Botting R. Inflammation and the mechanism of action of anti-inflammatory drugs. FASEB J 1987;1:89-96.

17. Guidera AC, Luchs JI, Udell IJ. Keratitis, ulceration, and perforation associated with topical nonsteroidal anti-inflammatory drugs. Ophthalmology 2001;108:936-44.

18. Asai T, Nakagami T, Mochizuki M, Hata N, Tsuchiya T, Hotta Y. Three cases of corneal melting after instillation of a new nonsteroidal anti-inflammatory drug. Cornea 2006;25:224-7.

19. Isawi H, Dhaliwal DK. Corneal melting and perforation in Stevens Johnson syndrome following topical bromfenac use. J Cataract Refract Surg 2007;33:1644-6.

20. Yamaguchi T, Murat D, Kimura I, et al. Diagnosis of steroid-induced glaucoma after photorefractive keratectomy. J Refract Surg 2008;24:413-5.

21. Javadi MA, Mirbabaei-Ghafghazi F, Mirzade M, Yazdani S, Yaseri M. Steroid induced ocular hypertension following myopic photorefractive keratectomy. J Ophthalmic Vis Res 2008;3:42-6.

22. Kitazawa Y, Tokoro T, Ito S, Ishii Y. The efficacy of cooling on excimer laser photorefractive keratectomy in the rabbit eye. Surv Ophthalmol 1997;(42 Suppl 1):S82-8.

23. Kitazawa Y, Maekawa E, Sasaki S, Tokoro T, Mochizuki M, Ito S. Cooling effect on excimer laser photorefractive keratectomy. J Cataract Refract Surg 1999;25:1349-55.

24. Niizuma T, Ito S, Hayashi M, Futemma M, Utsumi T, Ohashi K. Cooling the cornea to prevent side effects of photorefractive keratectomy. J Refract Corneal Surg 1994;10(2 Suppl):S262-6.

25. Neuffer MC, Khalifa YM, Moshirfar M, Miffin MD. Prospective comparison of chilled versus room temperature saline irrigation in alcohol-assisted photorefractive keratectomy. Nepal J Ophthalmol 2013;5:154-60.

26. Fujishima H, Yagi Y, Toda I, Shimazaki J, Tsubota K. Increased comfort and decreased inflammation of the eye by cooling after cataract surgery. Am J Ophthalmol 1995;119:301-6. 


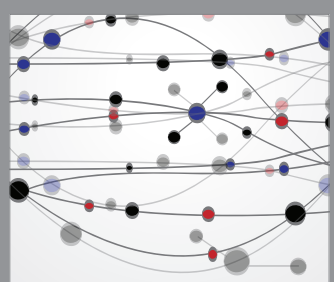

The Scientific World Journal
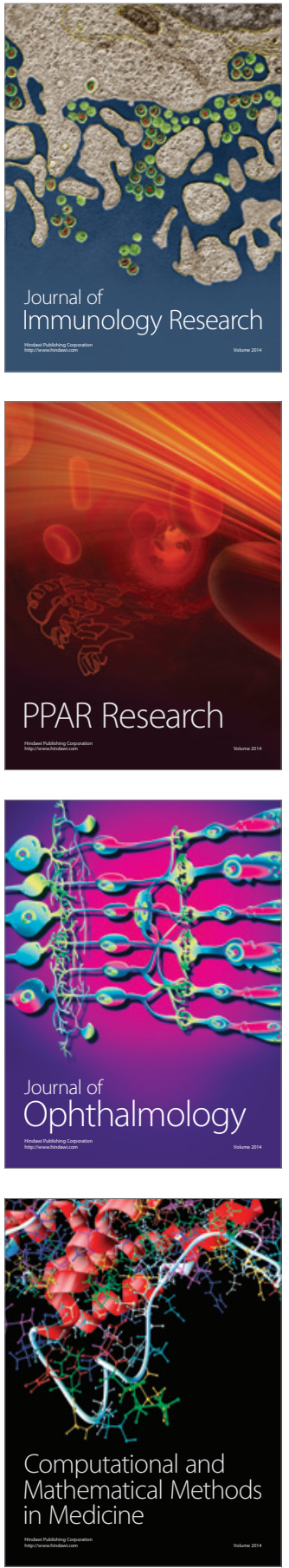

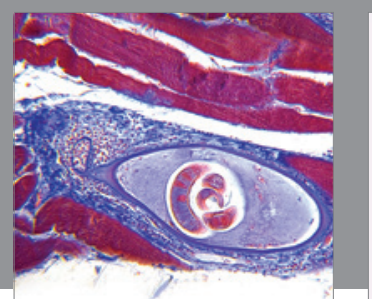

Gastroenterology Research and Practice

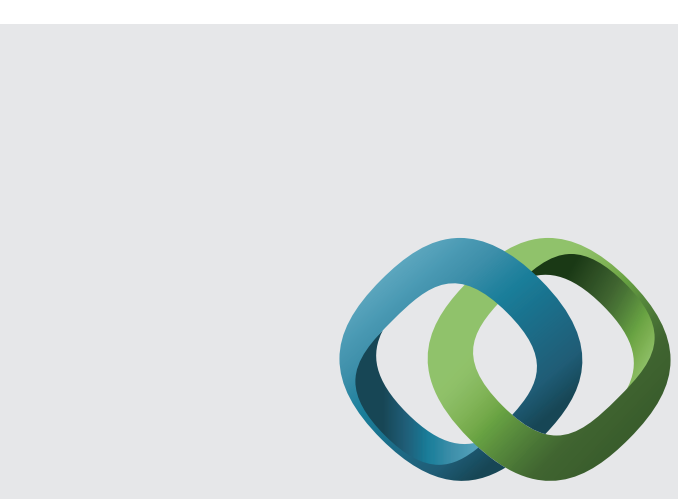

\section{Hindawi}

Submit your manuscripts at

http://www.hindawi.com
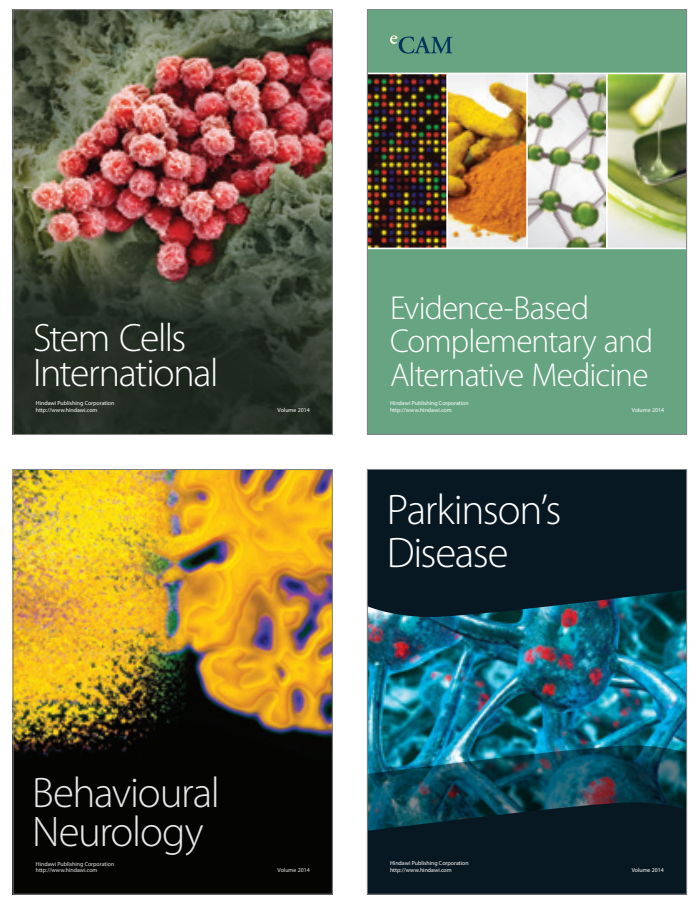
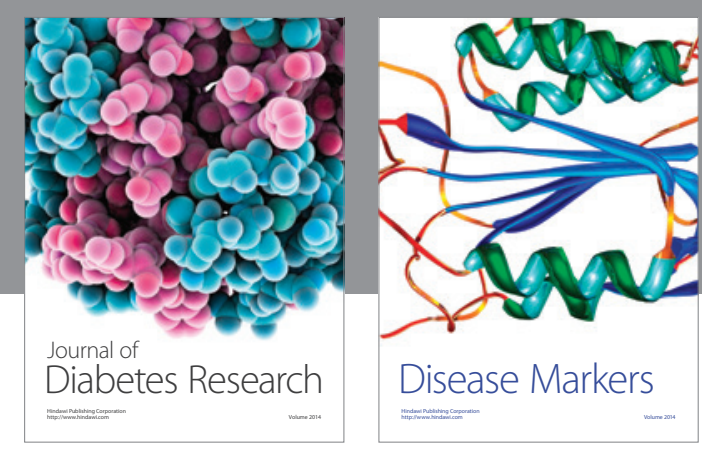

Disease Markers
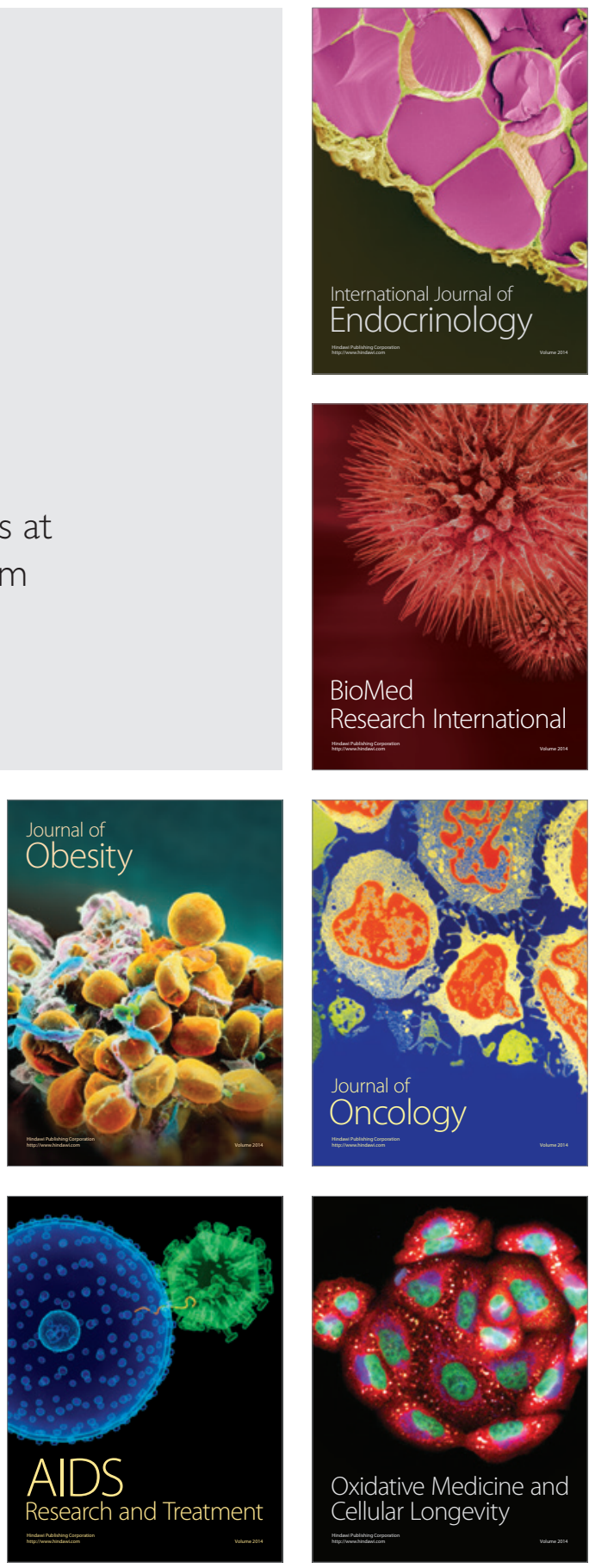